\title{
Los Alamos Learning Features of Simple and Complex Cells: A NATONAL LABORATORY Generative Approach via Multiplicative Interactions
}

\section{Overview}

\section{Goal:}

- A computational model to learn the feature bases

(receptive fields) of simple and complex cells in the primary visual cortex.

- Address the translation invariance developed from c

iे cells via natural image sequences.

क्ष Approach:

${ }_{\infty}$ Reconstruct an input via a linear combination of feature

\& bases in simple cells.

-Modulate the simple cell representation via multiplicative

\& interactions from complex cells.

- Enforce a sparseness prior for the latent representation

of of simple cells and complex cells.

on $\bullet$ Enforce a slowness prior and a trace-like rule for the

F representation of complex cells.

Advantages:

-Provided a factorized approach via the product of two-

order tensor weight parameters and only one latent

o variable for invariant representation, more efficient than

$\bar{\sigma}$ bilinear models that contain three-order tensor weight

$\because-$ parameters and two latent variables.

\% Demonstrated general simple cell feature maps and

is complex cell invariant receptive fields simultaneously.

\section{Generative model}

- Minimizing the sum of squared errors over images from s cells

$$
\min E_{0}: E_{0}=\frac{1}{2}\|\mathbf{x}(t)-\mathbf{A s}(t)\|_{2}^{2}
$$

- Multiplicative modulation 000000 c layer

\section{B}

$$
\left\{\begin{array}{l}
\mathbf{s}=\mathbf{y} \odot \mathbf{z} \\
\mathbf{y}=\mathbf{A}^{T} \mathbf{x} \\
\mathbf{z}=\mathbf{B} \mathbf{c}
\end{array}\right.
$$

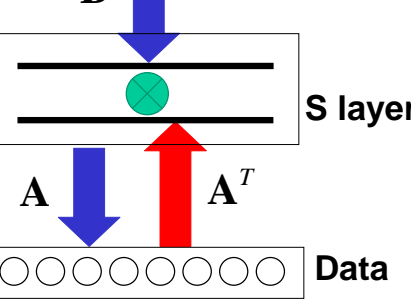

\section{Sparseness prior}

Sparse constraint of both $\mathrm{S}$ and $\mathrm{C}$ layers.

$$
\min E_{s p}: E_{s p}=\lambda_{c} \sum_{k}\left|c_{k}(t)\right|+\lambda_{y} \sum_{m}\left|y_{m}(t)\right|
$$

\section{Slowness prior}

Boost temporal autocorrelation for $\mathrm{C}$ cells

$$
\min E_{c r}: E_{c r}=\frac{\alpha}{2}\|\mathbf{c}(t)-\mathbf{c}(t-1)\|_{2}^{2}
$$

\section{Learn feature bases}

Total energy function $\min E: E=E_{0}$

$$
\left\{\begin{array}{l}
\frac{d \mathbf{c}(t)}{d t}=-\eta_{c} \frac{\partial E}{\partial \mathbf{c}(t)} \\
\frac{d \mathbf{A}}{d t}=-\eta_{A} \frac{\partial E}{\partial \mathbf{A}} \\
\frac{d \mathbf{B}}{d t}=-\eta_{B} \frac{\partial E}{\partial \mathbf{B}}
\end{array}\right.
$$$$
+E_{s p} \Rightarrow\left\{\frac{d \mathbf{A}}{d t}=-\eta_{A} \frac{\partial E}{\partial \mathbf{A}}\right.
$$$$
+E_{c r}
$$
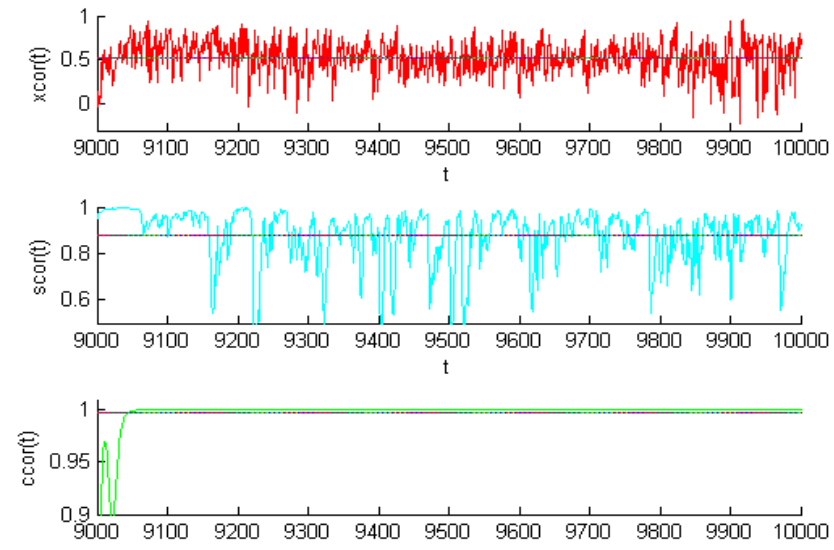

6. Experimental results

Natural image sequences

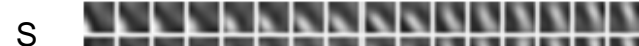

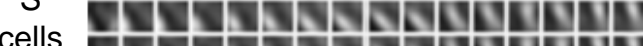

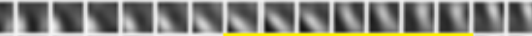
DH LHAD cen 100

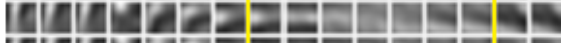

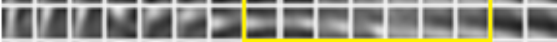

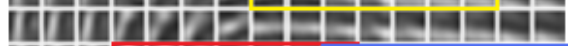
III

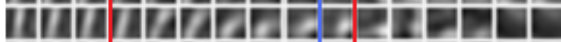

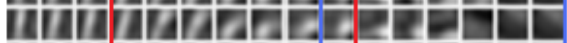

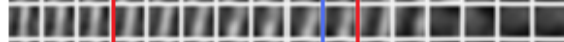
itintintrinta

C cells
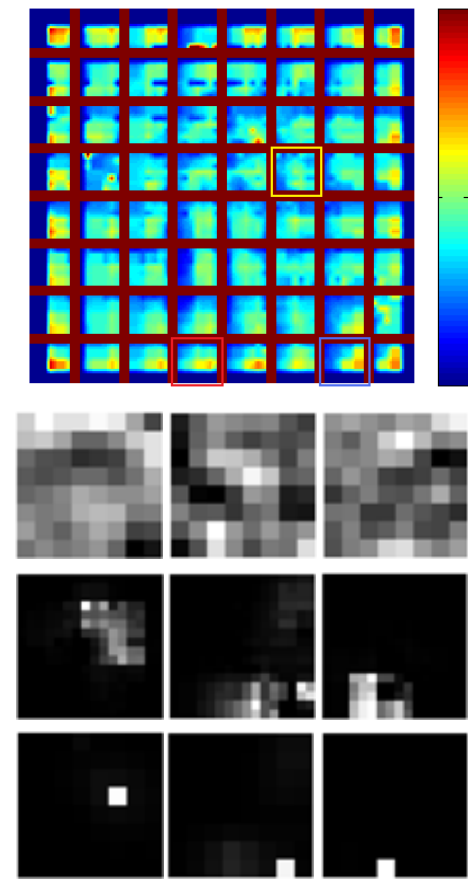